\title{
Restriction fragment length polymorphism typing of Mycobacterium tuberculosis
}

\author{
A C Hayward
}

Restriction fragment length polymorphism (RFLP) typing of Mycobacterium tuberculosis is a recently developed technique which allows strains of tuberculosis to be differentiated with a high degree of confidence. The application of this technique has enabled the patterns of transmission of tuberculosis to be elucidated with far greater certainty than was previously possible.

This review will discuss traditional methods of tracing the spread of tuberculosis, explain the technical principles behind RFLP typing, report on the literature validating its ability to differentiate strains of $M$ tuberculosis, and describe studies which have used RFLP typing to increase understanding of tuberculosis transmission. Current limitations, future potentials, and implications for clinical and public health practice will be discussed.

\section{Traditional methods of tracing the spread of tuberculosis}

The most basic method of tracing the spread of tuberculosis is follow up of contacts to see if they develop tuberculosis. Even if disease develops fairly soon after contact with tuberculosis, it is not possible to be certain whether infection was acquired from the suspected source.

Tuberculin sensitivity provides an indication of an individual's exposure to mycobacterial antigens in the past. The test cannot distinguish between exposure to tuberculosis from different sources. Tuberculin positivity can also be induced by exposure to environmental mycobacteria and by previous BCG vaccination. If conversion from a negative to a positive test can be documented, then recent infection is likely and it is possible to be more confident about the source of infection.

The limitations of traditional methods for following transmission of tuberculosis have led to efforts being made to find techniques which provide good strain differentiation allowing chains of transmission of $M$ tuberculosis to be documented.

Communicable Disease Surveillance Centre, London NW9 5EQ, UK

A C Hayward

Reveived 20 February 1995 Returned to authors 5 June 1995

Revised version received 26 June 1995

Accepted for publication

4 July 1995

\section{Mycobacterial strain differentiation}

Differentiation of mycobacteria to the species level has been possible for many years using classical microbiological techniques to evaluate phenotypic and biochemical characteristics.

Methods of strain differentiation within a species which have most often been used are testing of antibiotic sensitivity patterns and bacteriophage typing. Comparing antibiotic sensitivity patterns of isolates may prove useful in tracing spread of an unusual pattern of resistance. The technique is limited by the relatively low number of different sensitivity patterns possible and by the fact that mycobacterial strains may change their pattern of resistance when exposed to antituberculous drugs. ${ }^{1}$ Bacteriophage typing is hampered by the low number of bacteriophage types identified. ${ }^{2}$ Plasmid profiling has not proved possible in $M$ tuberculosis because of the low number or absence of plasmids. ${ }^{3}$ Serotyping cannot differentiate between infection with distinct strains of the $M$ tuberculosis complex. ${ }^{4}$ Other techniques for typing mycobacteria have included electrophoresis of cell proteins ${ }^{5}$ and biochemical heterogeneity. ${ }^{6}$ These techniques suffer from problems of reproducibility and low numbers of different types.

\section{Principles of RFLP typing}

RFLP typing is a technique which enables distinct "fingerprints" to be made which reflect the genetic constitution of the organism being typed. The success of RFLP typing depends on: (1) the existence of multiple copies of identical sections of DNA (insertion sequences) within the chromosome; (2) an enzyme which will recognise a sequence of base pairs that is unique to the insertion sequence and which will cut the DNA at that point (a restriction endonuclease); and (3) a labelled segment of DNA which is complementary to (and will hybridise to) part of the insertion sequence (a probe).

A standardised method for RFLP typing is now well accepted. ${ }^{7}$ In this method the insertion sequence (IS6110) is a 1355 base pair segment of DNA. IS6110 differs from two other described insertion sequences, IS 986 and IS 987 , by only a few base pairs and in practice they can be considered to be identical. The restriction endonuclease (PvuII) cleaves at base pair 461 of IS6110. The probe recognises a section of insertion sequence to the right of the base pairs cleaved by PruII.

RFLP typing by the standard technique involves harvesting of mycobacteria from a cul- 

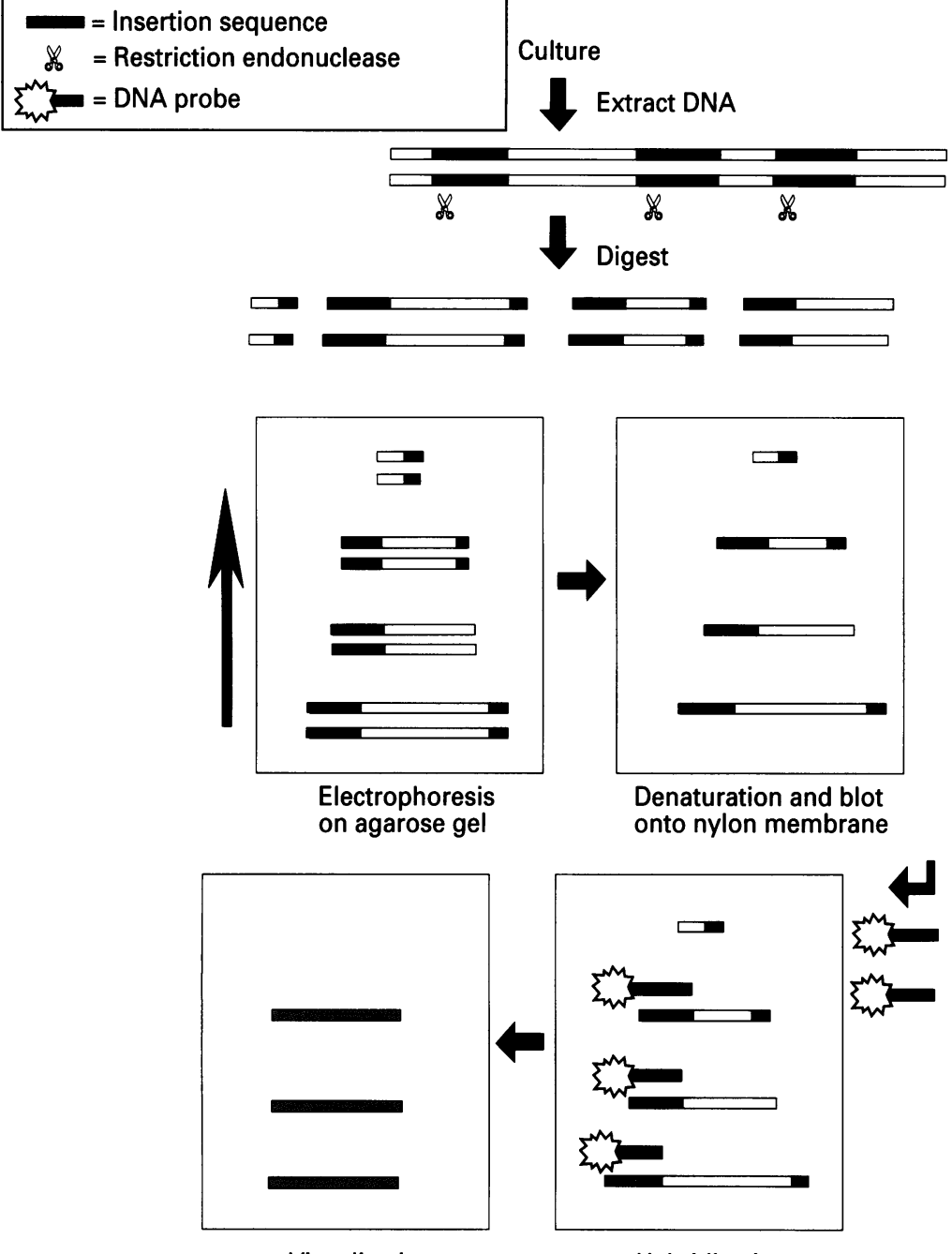

Visualisation
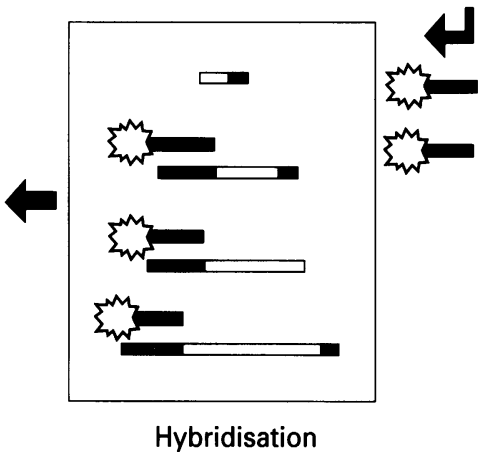

Hybridisation

Figure 1 Diagrammatic representation of RFLP typing of $M$ tuberculosis. DNA is extracted from cultured $M$ tuberculosis cells and digested using a restriction endonuclease (e.g. PvuII) which cleaves at a specific base pair sequence in the insertion sequence (e.g. IS6110). The resulting fragments are run on an electrophoresis gel, denatured into singlestranded DNA, and blotted onto a nylon membrane where they are hybridised to a

labelled DNA probe. The labelling allows the position of the fragments to be determined.

The resulting pattern depends on the number of and distance between insertion sequences.

ture, extracting the chromosomal DNA, digesting the DNA with PvuII, and separating the resulting fragments using electrophoresis. The position of fragments of DNA on the gel used for electrophoresis depends on the molecular weight of the fragments. (Different molecular weight fragments arise because of the varying distances between insertion sequences.) These fragments of DNA are denatured into single-stranded DNA whilst still in situ on the electrophoresis gel. The fragments of single-stranded DNA are blotted onto a nylon membrane and the labelled single-stranded probe DNA added. This probe hybridises to specific sections of IS6110 allowing the position of the fragments to be determined. Thus, a banding pattern is obtained which reflects the number of copies of IS6110 and their position within the chromosome. Each copy of IS6110 should produce a separate band (figs 1 and 2).

The diversity of banding patterns arises from occasional mutations causing transposition or replication of insertion sequences resulting in strains with different patterns. The natural rate of these transpositions is low. ${ }^{8-11}$ The great

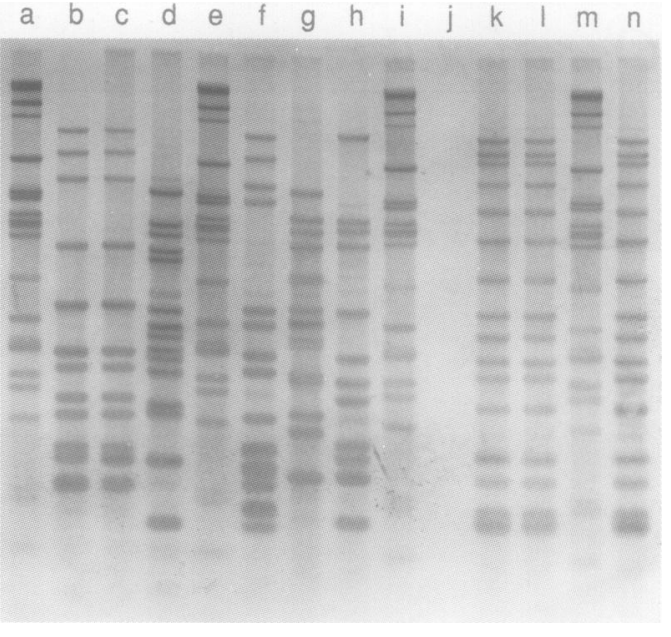

Figure 2 Photograph of RFLP banding patterns of isolates of $M$ tuberculosis. Lanes $a, e, i$, and $m$ are reference DNA. Lanes $k, l$, and $n$ have indistinguishable banding patterns and are epidemiologically linked. Lanes $b$ and $c$ have indistinguishable patterns but no epidemiological link was established. Reproduced with permission of Dr N Saunders, Virus Reference Division, Central Public Health Laboratories, Colindale, London.

diversity of fingerprints is likely to be a reflection of gradual genetic drift over centuries. If the insertion sequences were more readily transposed over short periods of time, then the usefulness of this technique would be diminished because, whilst passing through a chain of transmission, fingerprint patterns might change. Patterns of IS6110 have been found to be stable and to remain unchanged during passage through guinea pigs $^{8}$ and humans, ${ }^{9}$ even when drug resistance patterns have changed. ${ }^{1011}$ In one of these studies the fingerprint of one of the strains studied gained one extra band. ${ }^{9}$ Epidemiologically related cases of tuberculosis have been found to have identical banding patterns (or occasionally to differ by one band), whilst unrelated strains have been found to have diverse patterns. ${ }^{12-14}$

It has been shown that RFLP typing, using the IS6110 insertion sequence, can accurately identify strains which are epidemiologically related. The discriminatory power (the ability to distinguish between unrelated strains) of the technique is also of relevance. It is determined by the number of types which can be defined and the relative frequencies of these types. ${ }^{15}$ Studies typing large numbers of isolates from different parts of the world have found great diversity of the patterns of strains in populations $^{1216-22}$ and have not demonstrated any frequently encountered strains which were not associated with an outbreak. One study of strains in Tunisia ${ }^{23}$ commented on the fact that in one district there was much less heterogeneity of fingerprints than in other areas. This lack of heterogeneity in the district was based on only 17 out of 28 samples which shared four strain types. Such findings are consistent with the occurrence of several small unidentified outbreaks in the district.

Difficulties have been encountered in typing Asian isolates of $M$ tuberculosis because many strains from Vietnam ${ }^{24}$ and the Indian subcontinent have only one or a few copies of 


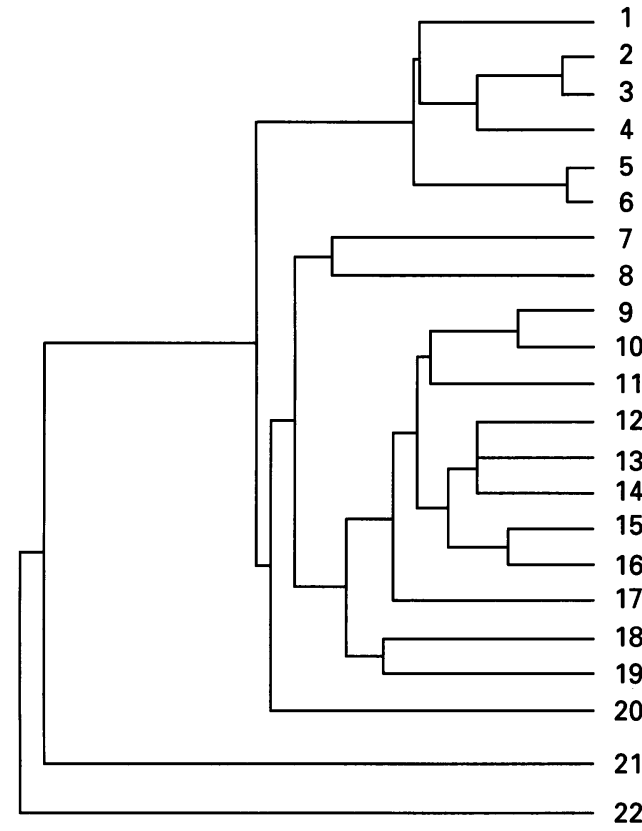

Figure $3 A$ dendogram representing the degree of similarity between a group of isolates. The scale represents similarity coefficients. Vertical lines mark the similarity coefficients between isolates. Isolates 2 and 3 were found to have identical banding patterns and isolates 5 and 6 differed by one band.

IS6110 (a few isolates of $M$ tuberculosis have been reported which have no $\operatorname{copy}^{25}$ ). Copies of IS6110 appear to insert preferentially in a region of the chromosome which is rich in small segments of DNA which are multiply repeated with only a small amount of DNA between copies (direct repeats). ${ }^{26}$ Because of this the degree of polymorphism which can be obtained when there are only a few copies of IS6110 is small. This has meant that RFLP typing using IS6110 alone has been unable to distinguish between some strains which have only one or two copies of IS6110. ${ }^{25}$ Additional typing using different insertion sequences, such as the 36-base pair direct repeat (DR) or the polymorphic GC-rich repetitive sequence (PGCRS), has been found to further differentiate some of these strains. ${ }^{25}$

\section{Comparison of RFLP banding patterns}

The consistency of electrophoresis gels may vary both within and between blocks of gel so that fragments of DNA of the same molecular weight may travel different distances. Internal markers are used which have fragments of known molecular weight against which the movement of the mycobacterial fragments can be standardised. This allows comparison of large numbers of isolates.

Computer software has been used to analyse banding patterns because visual comparison of isolates is difficult when the number of isolates is large. Patterns are standardised with reference to the markers and similarity coefficients between isolates are produced (a similarity coefficient of 1.0 theoretically indicates identical patterns). Dendograms can be constructed which graphically represent the similarity co- efficients between isolates, allowing them to be clustered into groups of similar patterns (fig 3). ${ }^{20}$ Visual inspection can then be used to decide which isolates amongst these groups are identical or differ by only one or two bands. In this way, large numbers of RFLP banding patterns can be compared and identical isolates identified. The degree of similarity between isolates can also be calculated. ${ }^{2728}$

\section{Applications of RFLP typing of $M$ tuberculosis}

Tracing identical strain types with RFLP typing has been used to demonstrate transmission of tuberculosis in hospital outbreaks, ${ }^{29-35} \mathrm{HIV}$ care institutions, ${ }^{3637}$ shelters for the homeless, ${ }^{3839}$ prisons $^{4041}$ and in whole communities. ${ }^{17-19}$ The technique has also been used to disprove suspected transmission. ${ }^{42}$

In population studies the number of isolates which are involved in clusters and the overall degree of similarity between strains has been used to infer the extent of, and risk factors for, active transmission of tuberculosis. ${ }^{1718}$

Comparison of the degree of similarity between strains from different geographical areas has been suggested as a method to elucidate the global epidemiology of tuberculosis. ${ }^{1216}$

The technique has also been used to answer questions about the relative importance of reinfection and relapse of disease, ${ }^{43-45}$ and to identify incidents of laboratory cross contamination. ${ }^{46}$

\section{INSTITUTIONAL OUTBREAKS OF TUBERCULOSIS \\ Hospitals}

Studies in American hospitals using RFLP typing have highlighted the potential for outbreaks of multidrug-resistant tuberculosis with high levels of mortality in HIV positive patients. ${ }^{29-34}$ Probable transmission in an HIV unit in Britain has also recently been documented using RFLP typing. ${ }^{36}$ These studies have demonstrated that risk factors for transmission in this setting include delayed diagnosis of the index case; delays in recognising drug resistance; inadequate isolation measures including poorly functioning air extraction systems in isolation rooms; and allowing infectious cases to be ambulatory on a ward. Patients who have spent longer periods on the same ward as infectious cases are more likely to become part of an outbreak than shorter stay patients. Other immunocompromised patients may also become involved in hospital outbreaks. An outbreak of fully sensitive tuberculosis amongst renal transplant patients on a renal unit has been described using RFLP typing. ${ }^{35}$ A suspected outbreak involving one member of staff and four patients treated at a renal unit in the UK was investigated using RFLP typing. ${ }^{42}$ The cases were related both in time and space, but were shown to have distinct RFLP types. This removed the need for an extensive investigation into the "outbreak".

Although most RFLP studies of nosocomial transmission of tuberculosis highlight the particular vulnerability of immunocompromised patients, immunocompetent contacts are also 
at risk. Tuberculin conversion rates in health care workers have been used to estimate the spread of infection (in America it is recommended that health care workers are regularly tuberculin tested as they are not routinely immunised with BCG). Such studies have emphasised bronchoscopy, intubation, respiratory support on a ventilator, ${ }^{47} 48$ pentamadine aerosolisation, ${ }^{49}$ sputum production techniques, ${ }^{49}$ late diagnosis, ${ }^{50}$ poor ventilation of rooms, ${ }^{48}$ draining abscesses, ${ }^{51}$ and necroscopic examination ${ }^{52}$ as risk factors for infection of health care workers. These findings have been considered in guidelines for prevention of nosocomial spread of tuberculosis. ${ }^{53}$ RFLP typing has been complemented by tuberculin skin testing in several studies, allowing spread of infection which has not led to active disease to be documented. Some of these studies have documented transmission of infection to immunocompetent health care workers during outbreaks of multidrug-resistant tuberculosis. ${ }^{29313234} \mathrm{HIV}$ positive and HIV negative workers associated with such outbreaks have developed active tuberculosis. ${ }^{32}$

\section{HIV housing centres}

An outbreak of tuberculosis sensitive to all first line antibiotics in a housing facility for HIV positive people was investigated using RFLP typing. ${ }^{37}$ The index case had respiratory symptoms for three weeks before diagnosis. Of 30 residents exposed, active tuberculosis developed in $11(37 \%)$, all of whom had similar RFLP types. This demonstrates that, given the right conditions, a single case of tuberculosis can rapidly lead to disease in many others. Without the RFLP typing it could have been argued that some of the cases were due to reactivation of old infection or that there was more than one primary case. Four residents had newly positive tuberculin skin tests and, out of 28 staff, at least six had positive tuberculin tests and one developed tuberculosis after the study period.

\section{Prisons}

An outbreak of multidrug-resistant tuberculosis amongst HIV positive inmates of a prison in New York and in a member of staff (who had received treatment for cancer and had a low CD4 count) has been reported. Isolates were found to have identical RFLP patterns, reinforcing the evidence that the cases were directly related. ${ }^{40}$

RFLP typing of tuberculosis isolates from a Californian prison revealed three distinct RFLP patterns among eight prisoners. Those with identical patterns were not present at the prison at the same time. This could imply that they were part of larger outbreaks which went unrecognised, perhaps because of the frequent movement of inmates between prisons. ${ }^{41}$

Shelters for the homeless

High rates of tuberculosis have been documented in several shelters for the homeless in Ohio. ${ }^{38}$ In one of these, an outbreak was confirmed with RFLP typing. Interestingly, two of the tuberculosis cases who were not thought to be associated with the home and were chosen as controls were found to have the same pattern. These two patients were from the same city and had a history of alcohol abuse.

A survey of RFLP strains of tuberculosis isolates from users of homeless shelters in Melbourne ${ }^{11}$ found 18 out of 19 to be identical. This demonstrated that, in this situation, the high rates of tuberculosis amongst the homeless was largely due to active transmission rather than reactivation of old infection.

A total of 227 isolates from newly diagnosed cases of tuberculosis in Australia from the first half of 1991 were also examined. Six of these isolates were found to have the same strain as the homeless men. This prompted an investigation to determine whether these people had any links with homeless shelters. Epidemiological links to the homeless shelters were found in all six (one had stayed in a shelter, one was a kitchen worker in a shelter, two alcoholic men and an elderly man lived near a shelter, and a nurse worked in an emergency room near a large shelter).

\section{COMMUNITY STUDIES OF TUBERCULOSIS} TRANSMISSION

Typing of community isolates of tuberculosis have demonstrated identical strains in next door neighbours ${ }^{54}$ (where the index case was non-compliant with treatment) and in family outbreaks. ${ }^{55}$ RFLP typing has also been used as a systematic tool to identify unexpected clusters of cases of tuberculosis within defined geographical areas. In many cases the links would not have been identified with conventional contact tracing.

An RFLP study of isolates from 18 noninstitutionalised HIV positive men found that six patients had the same RFLP patterns. Three bars were the only identifiable links between these cases. Two men worked as bartenders and one worked in a restaurant adjoining the bar; the others frequently visited one or more of the bars. ${ }^{56}$

A study of 163 patients in Berne ${ }^{19}$ found 45 who were potentially linked on the basis of RFLP studies. In the largest group 22 patients were identified with identical RFLP patterns. Within this group there were three subgroups: one consisted of homeless persons, drug addicts and alcoholics who were all frequent users of Berne's public support services; the second group centred round a restaurant where a waitress and the owner as well as several regular customers contracted tuberculosis (one regular customer who had a bloodstained cough for six months was a close contact of a member of the cluster associated with homelessness, drug abuse and alcoholism); the third subgroup consisted of two patients who did not fit into the other subgroups.

A survey of strains of tuberculosis in San Francisco ${ }^{18}$ revealed three clusters of more than 10 individuals. In the largest of these, 12 of the 30 cases were already known to be as- 
sociated with an HIV care institution. Specific links could be identified in half of the remaining cases. Links included naming another patient as a contact and care on the same hospital ward or clinic. The apparent index case was a 38 year old white man with AIDS who was not compliant with antituberculous treatment and remained sputum smear positive for around six months.

The second largest cluster contained 23 patients who were primarily young men born in the United States. Thirteen patients had AIDS and eight were substance abusers. The index case was a 28 year old white HIV-infected transsexual man who was an intravenous drug abuser and a prostitute.

In the third group, the index case was a 36 year old HIV seronegative black alcoholic man who was a frequent user of homeless shelters, detoxification centres, public clinics, and hospitals. He was non-compliant with therapy and had positive sputum smears for nine months. Most of the other patients in this cluster were also black, HIV seronegative alcoholics.

Community studies have used RFLP clustering to estimate the extent of and risk factors for transmission of tuberculosis. A New York study ${ }^{17}$ of tuberculosis patients at a major hospital in the Bronx found that $37.5 \%$ of isolates fell into 12 clusters with at least two isolates in each. The San Francisco study ${ }^{18}$ estimated that around a third of cases in the city were due to recent transmission (as inferred from RFLP clustering). In both studies patients who were older or foreign born were less likely to be in clusters. This suggests that in these groups disease is more likely to be due to reactivation of disease than recent transmission (although foreign born cases may have recently been infected by a person living abroad whose isolate is not available for typing). Both studies found that independent risk factors for transmission were being HIV positive, being young, and being a member of a particular racial or ethnic group. The ethnic groups identified were different in the two studies. The New York study also found that multidrug-resistant isolates were more likely to be clustered and that residence in an area where the average wage was low was a risk factor for recent transmission of tuberculosis.

POPULATION DIFFERENCES IN RFLP PATTERNS OF $M$ TUBERCULOSIS

RFLP diversity is thought to be due to near random mutations involving transpositions, replications, and deletions of insertion sequences. The degree of similarity between RFLP patterns may act as a marker for evolutionary distance between isolates. This aspect of RFLP analysis has been addressed in studies in which isolates from particular geographical regions of the world have been found to have many similarities with other isolates from those areas, but not with strains from geographically distinct areas. This phenomenon has been noted when comparing Dutch strains with African strains, ${ }^{12}$ and comparing strains from different regions of Japan. ${ }^{16}$ The degree of sim- ilarity between African strains (from Rwanda, the Central African Republic, and Burundi) has been found to be greater than the degree of similarity between Dutch strains. ${ }^{12}$ This is explained by the fact that, in countries where tuberculosis is very prevalent, a higher proportion of tuberculosis is due to recent infection than to reactivation.

\section{Other uses of RFLP typing of $M$ tuberculosis}

RFLP typing of sequential isolates from patients with recurring tuberculosis has demonstrated that in HIV positive patients this recurrence is often not due to reactivation of disease, but to reinfection with a new strain. ${ }^{44} 45$ RFLP typing has been used to confirm suspicions of laboratory cross contamination. ${ }^{46}$ Two incidents of suspected cross contamination involving six patients were confirmed by finding identical RFLP patterns. Cross contamination occurred in samples which were processed immediately after a heavily positive acid fast bacilli smear. The false positive cultures were positive only in BACTEC bottles and yielded no growth on the accompanying Lowenstein-Jensen slants. Information was fed back to clinicians who were able to stop or avoid inappropriate treatment.

\section{Limitations of RFLP typing of $M$ tuberculosis}

Although studies in many different areas of the world have demonstrated great heterogeneity of RFLP types, such large scale studies have not been conducted in England and Wales. It is not known whether there are any common community RFLP types in the UK. Until more is known about the distribution of strains, interpretation of findings needs to be cautious.

The following hypothetical example illustrates how care is needed in interpreting results. All isolates of $M$ tuberculosis received in a hospital laboratory during a six month period were typed using RFLP. Of 20 isolates two (from patients $A$ and $B$ ) were identical. Patients $A$ and $B$ were HIV positive and had been on the same ward when patient $A$ was receiving pentamidine nebulisers. One month later patient $\mathrm{A}$ was diagnosed as having tuberculosis. Patient B was diagnosed three weeks after this. From this evidence it seems likely that patient $A$ infected patient $B$ and that the pentamidine nebuliser may have been instrumental in this event. However, other scenarios could have explained the banding patterns observed, for example:

(1) Patient B was producing mycobacteria at the time of the contact but had very few symptoms so had not been diagnosed. Patient A, who was severely immunocompromised, developed rapidly progressive disease soon after being infected by patient $B$.

(2) Patient A infected C at a bar. Patient B was a frequent customer at the bar and contracted tuberculosis from C. 
(3) A hospital porter (D) was a heavy smoker and was being investigated for a chronic cough and weight loss at another hospital. $\mathrm{D}$ had tuberculosis and infected patients $A$ and $B$.

(4) Samples from patients A and B were both processed for RFLP typing on the same day. Cross contamination occurred.

(5) Patients A and B both had a strain of tuberculosis which was common in the community. The apparent epidemiological link was coincidental.

The example illustrates how RFLP typing results need to be interpreted in the light of clinical and epidemiological information, and how interpretation can be made more reliable by knowing the typing results of isolates from a geographically defined area rather than from just one hospital.

Because RFLP typing depends on culturing $M$ tuberculosis to provide enough DNA, it is a slow process. Standard culture techniques may take six weeks or longer. This may not be important in most epidemiological studies but limits its use as a clinical tool. RFLP typing is a labour intensive process and is therefore moderately expensive. The unit cost drops if large numbers of isolates are typed.

RFLP typing can help to describe an outbreak of tuberculosis but cannot determine how many people have developed latent infection. It is generally accepted that around $5 \%$ of infected immunocompetent people develop active disease in the two years following infection and a further $5 \%$ develop disease in later life. Tuberculin testing remains the best way of tracking latent infection.

\section{Future developments}

RFLP typing methods using DNA generated by the polymerase chain reaction (PCR) are being developed by several groups. ${ }^{57-62}$ This technique can provide typing results in days rather than weeks and allows non-viable cultures and archival tissue specimens to be typed. Problems with discriminatory power, reproducibility, and cross contamination still exist.

Several countries are developing databases of RFLP patterns of all their tuberculosis isolates. These will allow the patterns of strains in the country to be described. In particular, it will determine whether any strain types are particularly common, allowing more reliable interpretation of results. A national database of strains of $M$ tuberculosis has already been introduced in The Netherlands. Tuberculosis surveillance using RFLP databases has the potential to detect outbreaks of tuberculosis. Although there would inevitably be some delay (which could be reduced if more rapid PCRbased techniques become routine), the nature of tuberculosis outbreaks is that they can occur over extended time periods so that this approach could still allow valuable interventions to be made. A situation where a non-compliant or undiagnosed patient remains infectious for a prolonged period resulting in illness in others may only come to light through the results of RFLP typing. The potential for this is demonstrated by the results of the large study in San Francisco ${ }^{18}$ where up to $6 \%$ of cases of tuberculosis in the city arose from one noncompliant index case. In addition, such surveillance could highlight infection control policies which are inadequate to prevent nosocomial transmission of tuberculosis. Comparison of such databases from various countries may help to elucidate the global epidemiology of tuberculosis.

\section{Implications for clinical and public \\ health practice}

Although spread of tuberculosis in institutional settings was well recognised before the use of RFLP typing, accurate strain identification has provided much more convincing evidence of spread, particularly in outbreaks of multidrugresistant tuberculosis in institutions caring for HIV positive people. The results of RFLP typing in conjunction with more traditional epidemiological techniques can allow robust descriptions of outbreaks to be made. The added certainty provided by this technique can limit arguments about other explanations for a series of cases and thus help to convince decision makers to take appropriate action. In at least one hospital the strength of the results of one such study has led to tightening of hospital infection control procedures and a subsequent decline in the level of multidrug-resistant tuberculosis in the hospital. ${ }^{32}$ Conversely, if cases in an institution are found to be sporadic, then this could prevent unnecessary intervention. ${ }^{42}$

Application of American recommendations (from the Centers for Disease Control (CDC)) for prevention of nosocomial transmission of tuberculosis ${ }^{53}$ would be very expensive in the UK, even if the measures were confined to specialised centres. These recommendations include: the use of negative pressure rooms to isolate infectious patients and to perform bronchoscopy, sputum inductions and nebulised pentamidine treatments; the use of high efficiency filters in potentially contaminated general use areas (such as chest clinic waiting areas) and the use of disposable particulate respirators (a face mask designed to filter out particles $1-5 \mu \mathrm{m}$ in diameter). The appropriateness of such extensive control measures to the situation in England and Wales is not known, largely because the extent of nosocomial transmission remains undescribed. A large scale RFLP typing study in the UK would help to quantify nosocomial spread; such a study is currently being organised by the Public Health Laboratory Service. An incident of probable nosocomial transmission of tuberculosis between HIV positive patients has recently been described in a London hospital. ${ }^{36}$ Monitoring of the HIV epidemic and of levels of multidrug-resistant tuberculosis will also provide vital information. Until the situation is clearer, British Thoracic Society guidelines ${ }^{6364}$ should be adhered to.

The fact that current techniques may take more than two months to determine drug sensi- 
tivity patterns has been a major problem in the management of multidrug-resistant tuberculosis, particularly in the United States. By the time drug sensitivities are known the patient may have died from the disease and is likely to have remained highly infectious during his illness. Knowing that a patient's isolate had the same RFLP banding pattern as another patient with multidrug-resistant tuberculosis would allow effective chemotherapy to be started much sooner, improving chances of survival and substantially decreasing the period of infectivity. Culture followed by RFLP typing is already faster than culture followed by sensitivity testing. PCR-based RFLP typing should provide much faster answers in the future. A national system of RFLP typing, concentrating on patients thought to be at high risk of drug resistant tuberculosis, has recently been proposed. ${ }^{6566}$

RFLP studies have provided evidence for transmission of tuberculosis in situations where spread would previously have been thought unlikely, such as in restaurants and bars. The vulnerability of HIV positive people to tuberculosis has been demonstrated and this raises questions as to how extensive contact tracing should be in groups with a high incidence of HIV. RFLP typing studies have emphasised the importance of schemes to improve compliance (such as directly observed chemotherapy) by demonstrating how many people can be infected by a non-compliant patient. Groups where transmission of tuberculosis is common have been identified using RFLP typing. Such groups could be targeted for public health interventions.

\section{Conclusions}

RFLP typing of $M$ tuberculosis has been demonstrated to be a useful epidemiological tool and is likely to have increasing influence on clinical practice. Its main drawbacks are the delay in producing results (due mainly to the delay in culturing the organism) and the moderate expense. At a local level the technique may be used to confirm suspected outbreaks and identify previously unsuspected incidents of transmission. Future developments of the technique may allow early recognition of multidrug-resistant tuberculosis. Large scale studies can identify groups and situations in which active transmission occurs and allow estimates of the extent of the problem to be made. Surveillance of RFLP types has the potential to identify outbreaks of tuberculosis allowing control measures to be implemented. We are still some way from using RFLP typing routinely in the UK, but the technique is likely to become increasingly widely used and has the potential to strongly influence tuberculosis control policy in hospitals and at district and national levels.

The author would like to thank Dr John Watson (PHLS, CDSC) for his invaluable comments on the paper and Dr Nicholas Saunders (PHLS, CPHL Virus Reference Division) for advice on technical aspects of RFLP typing.

1 Reves R, Blakey D, Snider DE, Farer LS. Transmission of multipledrug-resistant tuberculosis: report of a school and community outbreak. Am ₹ Epidemiol 1981;113:423-35.
2 Snider DE, Jones WD, Good RC. The usefulness of phage typing Mycobacterium tuberculosis Isolates. Am Rev Respir Dis 1994;130:1095-9.

3 Zainuddin ZF, Dale JW. Does Mycobacterium tuberculosis have plasmids? Tubercle 1990;71:43-9.

4 Grange JM, Laszlo A. Serodiagnostic tests for tuberculosis: a need for assessment of their predictive accuracy and a need for assessment of their predictive accuracy

5 Millership SE, Want S. Whole-cell protein electrophoresis for typing Mycobacterium tuberculosis. F Clin Microbiol 1992 30:2784-7.

6 Hoffner SE, Svenson SA, Norberg R, Dias F, Ghebremichae $\mathrm{S}$, Kallenius G. Biochemical heterogeneity of $\mathrm{Myco}$ bacterium tuberculosis complex isolates in Guinea-Bissau. $\mathcal{F}$ Clin Microbiol 1993;31:2215-7.

7 van Embden JDA, Cave MD, Crawford JT, Dale JW, Eisenach KD, Gicquel B, et al. Strain identification of Mycobacterium tuberculosis by DNA fingerprinting: recommendations for a standardised methodology. $尹$ Clin Microbiol 1993;31:406-9.

8 Hermans PWM, van Soolingen D, Dale JW, Schulitema AR, McAdam RA, Catty D, et al. Insertion element IS 986 from Mycobacterium tuberculosis: a useful tool for diagnosis and epidemiology of tuberculosis. F Clin Microbiol 1990 28:2051-8.

9 Cave MD, Eisenbach KD, Templeton G, Salfinger $M$, Mazurek G, Bates JH, et al. Stability of DNA fingerprint pattern produced with IS6110 in strains of Mycobacterium tuberculosis. F Clin Microbiol 1994;32:262-6.

10 Godfrey-Faussett P, Stoker NG, Scott JAG, Pasvol G Kelly P, Clancy L. DNA fingerprints of Mycobacterium tuberculosis do not change during the development of tuberculosis do not change during the development of

11 Rastogi N, Ross BC, Dwyer B, Goh KS, Clavel-Seres S, Jeantils V, et al. Emergence during unsuccessful chemotherapy of multiple drug resistance in a strain of $M y c o-$ bacterium tuberculosis. Eur $\mathcal{F}$ Clin Microbiol Infect Dis 1990 40:323-30.

12 van Soolingen D, Hermans PWM, de Haas PEW, Soll R van Embden JDA. Occurrence and stability of insertion sequences in Mycobacterium tuberculosis complex strains: evaluation of an insertion sequence-dependent DNA polymorphism as a tool in the epidemiology of tuberculosis. f Clin Microbiol 1991;29:2578-86.

13 Mazurek GH, Cave D, Eisenach KD, Wallace RJ, Bates JH, Crawford JT. Chromosomal DNA fingerprint patterns produced with IS6110 as strain-specific markers for epidemiologic study of tuberculosis. F Clin Microbiol 1991 29:2030-3.

14 Otal I, Martin C, Vincent-Levy-Frebault V, Thierry D, Gicquel B. Restriction fragment length polymorphism analysis using IS6110 as an epidemiological marker in tuberculosis. $¥$ Clin Microbiol 1991;29:1252-4.

15 Hunter PR, Gaston MA. Numerical index of the discriminatory ability of typing systems: an application of Simpson's index of diversity. $¥$ Clin Micmbiol 1988;26: 2465-6.

16 Takahashi M, Kazumi Y, Fukasawa Y, Hirano K, Mori T, Dale JW, et al. Restriction fragment length polymorphism analysis of epidemiologically related Mycobacterium tuberculosis isolates. Microbiol Immunol 1993;37:289-94.

17 Alland D, Kalkut GE, Moss AR, McAdam RA, Hahn JA Bosworth W, et al. Transmission of tuberculosis in New York City. N Engl f Med 1994;330:1710-6.

18 Small PM, Hopewell PC, Singh SP, Paz A, Parsonnet J, Ruston DC, et al. The epidemiology of tuberculosis in San Francisco. N Engl ₹ Med 1994;330:1702-9.

19 Genenwein A. Telenti Al Bernasconi C, Mordasini C, Weiss S, Maurer A, et al. Molecular approach to identifying route of transmission of tuberculosis in the community. route of transmission of
Lancet 1993;342:841-4.

20 Godfrey-Faussett P, Stoker NG. Aspects of tuberculosis in Africa. 3. Genetic 'fingerprinting' for clues to the pathogenesis of tuberculosis. Trans $R$ Soc Trop Med 1993;86: 472-5.

21 Rigouts L, Portaels F. Restriction fragment length polymorphism analysis of drug resistant Mycobacterium tuberculosis strains isolated in Belgium. Acta Clin Belg 1994;49. 5-11.

22 Samper S, Oral I, Vitoria MA, Gomez-Lus R, Martin C. Aplicacion del RFLP a la tipificacion de cepas de C. Aplicacion del RFLP a la tipificacion de cepas de 1993;11:547-51.

23 Chevrel-Dellagi D, Abderrahaman A, Haltiti R, Koubaji H Gicquel B, Dellagi K. Large-scale DNA fingerprinting of Mycobacterium tubenculosis strains as a tool for epidemiological studies of tuberculosis. $\mathcal{f}$ Clin Microbiol 1993 31:2445-50.

24 Yuen LKW, Ross BC, Jackson KM, Dwyer B. Characterisation of Mycobacterium tuberculosis strains from Microbiol 1993;31:1615-8.

25 van Soolingen D, de Haas PEW, Hermans PWM, Groenen PMA, van Embden JDA. Comparison of various repetitive DNA elements as genetic markers for strain differentiation and epidemiology of Mycobacterium tuberculosis. $₹$ Clin Microbiol 1993;31:1987-95.

26 Hermans PWM, van Soolingen D, Bik EM, de Haas PEW, Dale JW, van-Embden JDA. Insertion element IS987 Dale JW, van-Embden JDA. Insertion element IS 987
from Mycobacterium bovis BCG is located in a hot-spot from Mycobacterium bovis BCG is located in a hot-spot
integration region for insertion elements in Mycobacterium integration region for insertion elements in Mycobacterium
tuberculosis complex strains. Infect Immun 1991;39:2695tuberch

27 Plikaytis BD, Plikaytis BB, Shinnick TM. Computer-assisted pattern recognition model for the identification 
of slowly growing mycobacteria including Mycobacterium tuberculosis. F Gen Microbiol 1992;138:2265-73.

28 Scmid J, Voss E, Soll DR. Computer-assisted methods of assessing strain relatedness in Candida albicans by fingerprinting with the moderately repetitive sequence $\mathrm{Ca} 3$. gerprinting with the moderately reperin Microbiol 1990;28:1236-43.

29 Beck-Sague C, Dooley SW, Hutton MD, Otten J, Breeden A, Crawford JT, et al. Hospital outbreak of multidrugA, Crawford JT, et al. Hospital outbreak of multidrugresistant Mycobacterium tuberculosis infections. Factors in
transmission to staff and HIV-infected patients. $¥ A M A$ transmission to st

30 Coronado VG, Beck-Sague CM, Hutton MD, Davis BJ, Nicholas P, Villareal C, et al. Transmission of multidrug resistant Mycobacterium tuberculosis among persons with human immunodefficiency virus infection in an urban hospital: epidemiologic and restriction fragment length polymorphism analysis. $\mathcal{F}$ Infect Dis 1993;168:1052-5.

31 Pearson ML, Jereb JA, Frieden TR, Crawford JT, Davis BJ, Dooley SW, et al. Nosocomial transmission of multidrugresistant Mycobacterium tuberculosis. A risk in patients and health care workers. Ann Intern Med 1992;117:191-6.

32 CDC. Nosocomial transmission of multidrug-resistan tuberculosis among HIV infected persons: Florida and New York, 1986-1991. MMWR 1991;40:585-90.

33 Edlin BR, Tokars JI, Grieco MH, Crawford JT, Williams J, Sordillo EM, et al. An outbreak of multidrug resistant tuberculosis among hospitalised patients with the acquired immunodeficiency syndrome. $N$ Engl f Med 1992;23: 1514-21.

34 CDC. Outbreak of multiple drug-resistant tuberculosis at a hospital - New York City, 1991. MMWR 1993;42: 427-35.

35 Jereb JA, Burwen DR, Dooley SW, Haas WH, Crawford JT, Gieter LJ, et al. Nosocomial outbreak of tuberculosis in a renal transplant unit: application of a new technique for restriction fragment length polymorphism analysis of Mycobacterium tuberculosis isolates. F Infect Dis 1993;168: 1219-24.

36 Kent RJ, Uttley AHC, Stoker NG, Miller R, Pozniak AL. Transmission of tuberculosis in British centre for patients infected with HIV. BMF 1994;309:639-40.

37 Daley CL, Small PM, Schecter GF, Schoolnik GK, McAdam RA, Jacobs WR, et al. An outbreak of tuberculosis dam RA, Jacobs WR, et al. An outbreak of tuberculosis with accelerated progression among persons infected with
the human immunodeficiency virus. $N$ Engl $₹$ Med 1992; the human

38 CDC. Tuberculosis among residents of shelters for the homeless - Ohio, 1990. MMWR 1991;40:869-77.

39 Dwyer B, Jackson K, Raios K, Sievers A, Wilshire E, Ros $B$. DNA restriction fragment analysis to define an extended cluster of tuberculosis in homeless men and their as sociates. F Infect Dis 1993;167:490-4.

40 CDC. Transmission of multidrug-resistant tuberculosis among immunocompromised persons in a correctional among immunocompromised persons in a correction

41 CDC. Tuberculosis transmission in a state correctional institution - California, 1990-1991. MMWR 1992;41: 927-9.

42 Bendall RP, Drobniewski FA, Jayasena SD, Nye PM, Uttley AHC, Scott GM. Restriction fragment length polymorphism analysis rules out cross-infection among ren patients with tuberculosis. F Hosp Infect 1995;30:51-6.

43 Daley CD. Tuberculosis recurrence in Africa: true relapse or re-infection? Lancet 1993;342:756-7.

44 Small PM, Shaper RW, Hopewell PC, Singh SP, Murphy MJ, Desmond E, et al. Exogenous reinfection with multidrug-resistant Mycobacterium tuberculosis in patients with drug-resistant Mycobacterium tuberculosis in patients with

45 Das S, Chan SI, Allen BW, Mitchison DA, Lowrie DB. Application of DNA fingerprinting with IS986 to sequential mycobacterial isolates obtained from pulmonary tuberculosis patients in Hong Kong before, during and after short-course chemotherapy. Tubercle Lung Dis 1993 74:47-51.
46 Small PM, McClenny NB, Singh SP, Schoolnik GK, Tompkins LS, Mickelsen PA. Molecular strain typing of Mycobacterium tuberculosis to confirm cross contamination in the mcyobacteriology laboratory and modification of procedures to minimize occurrence of false-positive culprocedures to minimize occurrence of 7 Clin Microbiol 1993;31:1677-82.

47 Cantanzaro A. Nosocomial tuberculosis. Am Rev Respir Dis 1982;125:559-62.

48 Ehrenkranz MD, Kicklighter JL. Tuberculosis in a general hospital: evidence for airborne spread of infection. Ann Intern Med 1972;77:377-82.

49 CDC. Mycobacterium tuberculosis. Transmission in a health clinic - Florida 1988. MMWR 1989;38:256-64.

50 Kantor HS, Poblete R, Pusateri SL. Nosocomial transmission of tuberculosis from unsuspected disease. $A m \mathcal{F}$ Med 1988;84:833-8.

51 Hutton MD, Stead WW, Cauthen GM, Bloch AR, Ewing WM. Nosocomial transmission of tuberculosis associated with a draining abscess. $\mathcal{F}$ Infect Dis 1990;161:286-95.

52 Lundgren R, Norrman E, Ashberg I. Tuberculosis infection transmitted at autopsy. Tubercle 1987;68:147-50.

53 Dooley SW, Castro KG, Hutton MD, Mullan RJ, Polde JA, Snider DE. Guidelines for preventing the transmission of tuberculosis in health-care settings, with special focus on HIV-related issues. MMWR 1990;39:RR-17.

54 Godfrey-Faussett P, Mortimer PR, Jenkins PA, Stoker NG. Evidence of transmission of tuberculosis by DNA fingerprinting. $B M \mathcal{F}$ 1992;305:221-3.

55 Thierry D, Matsiota-Bernard P, Pitsouni E, Costopoulos $C$, Guesdon JL. Use of the insertion element IS6110 for DNA fingerprinting of Mycobacterium tuberculosis isolates presenting various profiles of drug susceptibility. FEMS presenting various profiles of drug suscep

56 Tabet SR, Goldhaum GM, Hooton TM, Eisenach KD, Cave D, Nolan CM. Restriction fragment length polymorphism analysis detecting a community-based tuberculosis outbreak among persons infected with human immunodefficiency virus. $\mathcal{F}$ Infect $D$ is $1994 ; 169: 189-92$.

57 Editorial. PCR fingerprinting microbes by random amplification of polymorphic DNA. F Med Microbiol 1993; 39:161-2.

58 Telenti A, Marchesi F, Balz M, Bally F, Bottger EC, Bodmer T. Rapid identification of Mycobacteria to the species level by polymerase chain reaction and restriction enzyme level by polymerase chain reaction and res
analysis. $\mathcal{F}$ Clin Microbiol 1993;31:175-8.

59 Plikaytis BB, Plikaytis BD, Yakrus MA, Butler WR, Woodley CL, Silcox VA, et al. Differentiation of slowly growing Mycobacterium species, including Mycobacterium tuberculosis, by gene amplification and restriction fragmen length polymorphism analysis. $\mathcal{F}$ Clin Microbiol $1992 ; 30$. 1815-22.

60 Ross BC, Dwyer B. Rapid, simple method for typing isolates of Mycobacterium tuberculosis by using the polymerase chain reaction. $\mathcal{F}$ Clin Microbiol 1993;31:329-34.

61 Plikaytis BB, Crawford JT, Woodley CL, Butler WR, Eisenach $\mathrm{KD}$, Cave $\mathrm{MD}$, et al. Rapid amplification-based senach $\mathrm{KD}$, Cave $\mathrm{MD}$, et al. Rapid amplification-based fingerprinting of $M y$

62 Haas WH, Butler WR, Woodley CL, Crawford JT. Mixedlinker polymerase chain reaction: a new method for rapid fingerprinting of isolates of the Mycobacterium tuberculosis complex. F Clin Microbiol 1993;31:1293-8.

63 Joint Tuberculosis Committee of the British Thoracic Society. Guidelines on the management of tuberculosis and

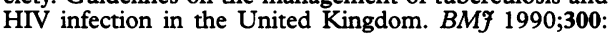
995-9.

64 Joint Tuberculosis Committee of the British Thoracic Society. Control and prevention of tuberculosis in the United Kingdom: Code of Practice 1994. Thorax 1994;49:1193200.

65 Davies PDO. Drug resistant tuberculosis. BMf 1995;310: 400-1.

66 Duerden BI. Drug resistant tuberculosis. BMf 1995;310 940 . 